\title{
Non-situational personal communication of preschool children during performance activities as a psychological condition for dialogical speech development
}

\author{
Gulnara Tiustina ${ }^{1, *}$, Tatiana Snegireva $^{2}$, and Anastasia Stepanenko $^{3}$ \\ ${ }^{1}$ Pedagogics Sciences, Department for Psychology of Education and Development, 628605, Nizhnevartovsk, Russia \\ ${ }^{2}$ Psychological Sciences, Department for Psychology of Education and Development, 628605, Nizhnevartovsk, Russia \\ ${ }^{3}$ Educator, Kindergarden № 25 «Semicvetik», 628615, Nizhnevartovsk, Russia
}

\begin{abstract}
The article presents the results of a study of psychological and pedagogical conditions for the development of dialogical speech in senior preschool children during performances. Adequacy of using non-situational-personal communication is justified. Possibilities of performance activities as conditions for the development of dialogical speech are described. The results are represented as development criteria and indicators for dialogical speech and comparison of their dynamics at the ascertaining and control stages of the experiment.
\end{abstract}

\section{Introduction}

At present, one of the priority tasks of the federal education policy is development of a socializing ability of children. The federal target program for the education development for 2016-2020 emphasizes the dissemination of modern models of socialization of children in all regions of the Russian Federation in order to ensure conditions for the development of Russian education aimed at creating a competitive human potential" [5].

The problem of speech development is one of the central ones in modern psychology and pedagogy. One of the speech functions, according to M.I. Lisina, is interindividual, or communicative, according to A.N. Leontyev and S.L. Rubinstein. Speech acts are the most perfect, accurate and fast-acting means of communication between people. "At preschool age, the communicative function of speech is carried out in the process of interaction with adults and peers which underlies the entire subsequent development of the preschooler," M.I. Lisina says. [3]. One of the main tasks of speech development of preschoolers is assimilation of dialogical speech. In the Federal State Educational Standard for Preschool Education, the problem of development of dialogical speech is associated with "the development of coherent, grammatically correct dialogical speech", "communication and interaction with adults and peers" [4].

The ontogenesis of dialogical speech in preschool childhood, development of speech as a means of communication, development of dialogical speech in preschool children in the context of various forms of communication with adults and peers were described by Russian and foreign scientists (N.A. Berdyaev, F. Rosenzweig, M.M. Bakhtin, E.I. Tikheeva, E.A. Flerina, L.S. Vygotsky, A.N. Leontiev, S.L. Rubinstein, D.B. Elkonin, A.V. Zaporozhets, M.I. Lisina, M. Montessori,
J. Piaget, A. Wallon, C. Rogers, J. Bruner and others). Speech development involves a number of stages; at each stage, there are changes in the forms of communication of preschoolers and their peers. In senior preschool children, two forms of communication with peers change: non-cognitive-cognitive and nonsituational-personal. At the level of non-situational cognitive communication, the most important means of communication is speech which enables to go beyond the boundaries of one particular situation and realize the "theoretical" cooperation that is the essence of the described form [3]. In 5-6-year-old children, there is a tendency towards the development of a non-situationalpersonal form of communication with peers that is not mediated by shared objects and actions. Friendship develops between children, an ability to empathize, to see mood of a communication partner, to give in to him. However, not all children develop such communication and personal attitudes. For many preschoolers, egoistic, competitive attitudes towards their peers remain predominant, which makes it difficult for children to build a dialogue with each other. Thus, the purposeful development of a non-situational-personal form of communication is the most important condition for the development of dialogue relations and dialogical skills.

The analysis of psychological and pedagogical literature made it possible to draw attention to theatrical activities used for speech development. Drama games, dramatization, directorial games provide significant examples of dialogical interaction, since they are built on the basis of literary works. Non-situational-personal communication of senior preschoolers during theatrical activities is a psychological mechanism for the development of dialogical speech and skills which makes it possible to use the powerful potential of theatrical games for the development of dialogical relations.

The development of dialogical speech in preschool children is complicated by existing contradictions

* Corresponding author: gerdzg@yandex.ru 
between the state education policy, requirements of the federal state educational standard for preschool education on the development of dialogical speech as a form of communication among children, and the demand for modern organizational forms, methods and technologies for developing dialogical speech as a form of communication within theatrical activities. These contradictions made it possible to formulate the initial problem of determining and analyzing psychological and pedagogical resources for the development of dialogical speech in senior preschool children through theatrical activities.

\section{Discussion}

The psychological basis for the development of speech of preschoolers is the theory of speech activity, based on the research by A.N. Leontiev, L.S. Vygotsky, M.I. Lisina, J. Piaget and others. The theory of speech activity studies speech as an active, focused and motivated activity, its functions, motives, relationship with thinking, processes of generation of speech utterances, speech mechanisms, types of speech (internal, external: a dialogue and a monologue), the ratio of language and speech, the process of mastering speech. [2].

J. Piaget believed that a dialogue is the main communication tool. He distinguished between "egocentric and socialized speech". Egocentric speech does not perform a communicative function, it accompanies communication. Socialized speech is addressed to the interlocutor to influence him and transmit information. The most important criterion for socialized speech is initiative, response and counterresponse. [7]. J. Piaget showed that in the preschool development period, children's dialogue is a heterogeneous, amorphous form of interaction with peers. Children learn basic features of this form of speech only at the late stages of preschool childhood.

M.I. Lisina studied the development of speech as a means of communication of children in the first 7 years of their lives and the formation of an interindividual function of speech in children. She identified three main stages: preverbal, speech production and development of speech communication. She believed that communicative factors play an important role in speech development. Therefore, when considering each stage of speech genesis, she focused on the communicative factor. She suggested that the communicative factor affects the development of the interpersonal function of speech in children, but this effect is manifested unequally and affects the stages of speech formation. This is primarily due to the fact that the communicative factor changes in different periods of preschool childhood. The study of speech genesis is carried out in the light of the concept of communication genesis which suggests two approaches to the speech development in children: understanding of communication and connection of speech with communication. The author developed a conceptual scheme of communication, applying the general theory of activity developed by A.N. Leontiev for the analysis of communication. The structural components of communication are as follows: subject, need, motives, actions, tasks, means, products [3]. The development of communication as a holistic activity was described as a change in qualitative forms. The form of communication is a communicative activity taken in an integral set of traits characterized by the following parameters: time of its occurrence during preschool childhood, a place in the child's life system, content of communication needs; motives, means of communication. M.I. Lisina identified four forms of communication of children and adults: situationalpersonal (the first six months of life), situationalbusiness ( 6 months - 3 years), non-situational-cognitive (3-5 years), non-situational-personal (6-7 years). The highest form of communicative activities is observed in preschool childhood. It is formed on the basis of personal motives that encourage children to communicate. Therefore, the emphasis is on this particular form of communication, which is characteristic of preschool age, and the purposeful development of non-situational-personal communication is considered as the most important condition for the dialogue, the development of dialogue skills in preschoolers.

The most important means of the development of dialogical speech is performance activities. According to Vygotsky, they are one of the effective means of development of the emotional sphere, emotional control and moral feelings. Theatrical and game activities based "on the action performed by the child himself, connect artistic creativity and personal experience" [1]. They meet children's needs for reincarnation, imitation, contribute to mental activities, mental processes, develop the emotional sphere. The dialogue as a form of socialized speech develops through theatrical activities. Literary samples of speech learned can be used by preschoolers as speech materials in communication with each other. Practical and formal aspects of verbal communication are assimilated. Playing together, children begin to take into account desires and actions of other children, defend their points of view, build and implement joint plans [8].

The play is a leading activity in preschool age. The theatrical play is an effective means of socio-emotional, verbal, artistic and aesthetic development. It is directly related to artistic activities which determine its "frontier" character (A.N. Leontyev). There are various approaches to the classification of theatrical activities: dramatization (dramatization of nursery rhymes, songs, fairy tales, literary works), performances (dramatic performance, musical dramatic performance, opera, choreographic performance, rhythmoplasty performance, pantomime), puppet theater plays, theatrical performances (holidays, entertainment, shows). Development of expressiveness of children's speech, pronunciation, an ability to intonate with a certain voice, to convey mood and state is crucial.

The main condition for the development of dialogical speech of senior preschool children in theatrical activities is systematic management. The tasks of the development of theatrical activities include creating conditions for the phased development of theatrical activities, use of various types of theatrical activities; familiarization with theatrical culture; development of artistic skills, etc. An environment must be organized for the development of theatrical activities. In accordance with the requirements of the federal state standard on preschool education, the developing subject-spatial environment should have a rich content, be transformable, multifunctional, varied, accessible and safe" [4]. In kindergarten groups, the subject-spatial environment is represented by centers or corners. The theatrical corner is an important object of the environment, since theatrical activities help unite children.

The development of dialogical speech based on nonsituational-personal communication in theatrical 
activities was the goal of the formative stage of the experiment, which was implemented on the basis of Nizhnevartovsk school 25 "Semitsvetik". The influence of an adult is of great importance for the development of non-situational-personal communication, the initiative moves child's activities to a higher level according to the principle of "zones of proximal development". Interaction in the form of theatrical activities develops dialogical speech. The following organizational and pedagogical conditions were taken into account: organization of a developing subject-spatial environment which acts as a stimulator, a driving force in the development of dialogical skills and speech; creation of a communicative-dialogue basis for the relationship of preschool children with adults and peers during theatrical activities. At the stage of preparation for a theatrical game, the teacher discusses actions to be performed, focuses on the need to take into account points of view of partners, to seek joint solutions. Thus, at the preparatory stage, children outline a general plan, learn to agree with each other. At the main stage, in the process of playing or staging various stories, they want to learn about characters and episodes. In addition, in performing various roles, children begin to see the subject from different angles. This contributes to the development of decentration - the most important mental ability used to generate different points of view [8]. At this stage, it is important to stimulate the natural desire of children to diversify knowledge gained from observations, books, and cartoons. Thus, the role interactions becomes informative, they use a variety of means of expression. The role played is accompanied by speech. The non-situational-personal form of communication between senior preschoolers is of great vital importance for them, as it allows children to satisfy the need to know themselves, other people, characters and enrich role-playing interaction between the players. Thus, through dialogical speech, the essence of role relationships can be revealed. In order to develop dialogical speech using a non-situational-personal form of communication, 5 fairy tales were used : "Kolobok","Cinderella","Puss in Boots","Snow Queen", and "Bremen Musicians". The development of play situations that integrate the semantic content of a nonsituational-personal form of communication and specifics of theatrical plays presupposed the determination of the place and time children were included in these situations. In this case, these were classes in a preparatory group with 6-7 year old children conducted in a playful form and built into the mode of educational activities of preschoolers. Each game situation had elements of problematization, suggesting interaction with peers and needs to include adults in the communication process. Adults should draw children's attention to the assessment of their dialogical skills; help them compare their skills with those of peers; teach them to compare their opinions and opinions of their peers. This organization of non-situational-personal communication activates child's consciousness, encourages him to look at himself from the side. This becomes possible when communication is based on real interests.

\section{Results}

The aim of the control stage of the experiment was to determine the dynamics of results of the development of dialogical speech in children of preschool age, which was carried out using the following diagnostic tools: the method "Study of dialogical speech based on plot pictures" (R.I. Lalaeva), the method "Speech features of preschoolers in communication with peers and adults" (A.G. Ruzskaya), the method "Features of coherent speech of preschoolers in communication with adults and peers" (S.N. Karpova, M.A. Stepanova), the method "Let's get acquainted" (T.S. Komarova, O.A. Solomennikova), the method "Conversation with a friend" (O.V. Dybina). The experiment involved 20 senior preschoolers. Let us describe quantitative and qualitative results of the control stage. Control results revealed positive changes in all the selected criteria and indicators for the development of dialogical speech in senior preschoolers [6].

The dynamics of indicator "Sociability" is presented in Table 1.

Table 1. The dynamics of indicator "Sociability" in 5-6 year-old children

\begin{tabular}{|c|c|c|c|c|c|c|}
\hline \multirow[t]{3}{*}{ Indicators } & \multicolumn{3}{|c|}{$\begin{array}{c}\text { Ascertaining } \\
\text { experiment }\end{array}$} & \multicolumn{3}{|c|}{ Control experiment } \\
\hline & \multicolumn{6}{|c|}{ Level (\%) } \\
\hline & .돌 & $\begin{array}{l}\Xi \\
\Xi \\
\Xi\end{array}$ & 3 & .ㅁํㄹ & $\stackrel{\Xi}{\Xi}$ & 3 \\
\hline $\begin{array}{l}\text { Initiative in } \\
\text { speech } \\
\text { interaction }\end{array}$ & 15 & 75 & 10 & 40 & 50 & 10 \\
\hline $\begin{array}{l}\text { Active } \\
\text { response, } \\
\text { desire to } \\
\text { maintain and } \\
\text { continue } \\
\text { verbal } \\
\text { communicati } \\
\text { on }\end{array}$ & 15 & 40 & 45 & 40 & 50 & 10 \\
\hline
\end{tabular}

A comparative analysis of the results presented in Table 1, indicate a positive dynamics in the formation of this criterion and its indicators in older preschoolers. At the control stage, the number of children with a high level increased and the number of children with a low level decreased. The high level was observed in $40 \%$, which is $25 \%$ higher than the results obtained at the ascertaining stage. Preschoolers who showed medium and high levels became more active in verbal interaction, interaction with their peers using various remarks: questions, messages. Many of them supported and continued verbal communication, eagerly talked on various topics, could keep up the conversation on the topic suggested, reacted more quickly to replicas, used various forms.

The dynamics of indicator "Ability to respond to any verbal form" is presented in Table 2.

Table 2. The dynamics of indicator "Ability to respond to any verbal form" in 5-6 year-old children

\begin{tabular}{|l|c|c|}
\hline \multirow{2}{*}{ Indicators } & $\begin{array}{c}\text { Ascertaining } \\
\text { experiment }\end{array}$ & $\begin{array}{c}\text { Control } \\
\text { experiment }\end{array}$ \\
\cline { 2 - 3 } & \multicolumn{2}{|c|}{ Level (\%) } \\
\hline
\end{tabular}




\begin{tabular}{|c|c|c|c|c|c|c|}
\hline & .000 & $\stackrel{\Xi}{\Xi}$ & $\underline{z}$ & . & $\stackrel{\Xi}{\Xi}$ & 3 \\
\hline $\begin{array}{l}\text { Relevant } \\
\text { answers }\end{array}$ & 15 & 55 & 30 & 40 & 50 & 10 \\
\hline $\begin{array}{l}\text { Tolerantl } \\
\text { responses to } \\
\text { a variety of } \\
\text { messages, } \\
\text { polite } \\
\text { expression } \\
\text { of } \\
\text { disagreemen } \\
\text { t }\end{array}$ & 15 & 30 & 55 & 35 & 25 & 40 \\
\hline $\begin{array}{l}\text { Verbal } \\
\text { expression } \\
\text { of } \\
\text { willingness } \\
\text { or accepted } \\
\text { forms of a } \\
\text { refusal }\end{array}$ & - & 40 & 60 & 40 & 35 & 25 \\
\hline
\end{tabular}

Table 2 shows a positive dynamics in the formation of this criterion and its indicators. At the control stage, the number of children with a high level increased, and the number of children with a low level decreased.

The dynamics of indicator "Ability to enter into dialogue with other people" is presented in Table 3.

Table 3. The dynamics of indicator " Ability to enter into dialogue with other people " in 5-6 year-old children

\begin{tabular}{|c|c|c|c|c|c|c|}
\hline \multirow[t]{3}{*}{ Indicators } & \multicolumn{3}{|c|}{$\begin{array}{c}\text { Ascertaining } \\
\text { experiment }\end{array}$} & & \multicolumn{2}{|c|}{$\begin{array}{c}\text { Control } \\
\text { experiment }\end{array}$} \\
\hline & \multicolumn{6}{|c|}{ Level (\%) } \\
\hline & $\frac{5000}{3}$ & : & 宐 & 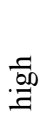 & 声 & 30 \\
\hline $\begin{array}{l}\text { Clear } \\
\text { questions }\end{array}$ & 5 & 35 & 60 & 20 & 55 & 25 \\
\hline $\begin{array}{l}\text { Share } \\
\text { impressions } \\
\text { with feelings, } \\
\text { opinions }\end{array}$ & 15 & 45 & 40 & 45 & 40 & 15 \\
\hline $\begin{array}{l}\text { Express } \\
\text { requests, } \\
\text { advice, } \\
\text { suggestions, } \\
\text { invitations } \\
\text { politely }\end{array}$ & 15 & 40 & 45 & 30 & 35 & 35 \\
\hline
\end{tabular}

Table 3 shows a positive dynamics in the formation of this criterion and its indicators. At the control stage, the number of children with a high level of the indicators increased by $15 \%$ (an ability to pose clear questions); by $30 \%$ (an ability to share impressions, feelings, opinions); by $15 \%$ (an ability to express requests, suggestions, invitations). Accordingly, the number of children, with a low level of these indicators decreased by $35 \%, 25 \%$ and $10 \%$, respectively.

The dynamics of indicator "Ability to observe dialogue rules" is presented in Table 4.
Table 4. The dynamics of indicator "Ability to observe dialogue rules " in 5-6 year-old children

\begin{tabular}{|c|c|c|c|c|c|c|}
\hline \multirow[t]{3}{*}{ Indicators } & \multicolumn{3}{|c|}{$\begin{array}{l}\text { Ascertaining } \\
\text { experiment }\end{array}$} & & \multicolumn{2}{|c|}{$\begin{array}{c}\text { Control } \\
\text { experiment }\end{array}$} \\
\hline & \multicolumn{6}{|c|}{ Level (\%) } \\
\hline & .0ㅐㄹ & $\begin{array}{l}\text { 莺 } \\
\text { छ }\end{array}$ & $\underline{3}$ & .000 & 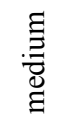 & 孞 \\
\hline $\begin{array}{l}\text { Compliance } \\
\text { with } \\
\text { dialogue } \\
\text { rules }\end{array}$ & 15 & 40 & 45 & 25 & 55 & 20 \\
\hline $\begin{array}{l}\text { Knowledge } \\
\text { of speech } \\
\text { etiquette }\end{array}$ & 15 & 40 & 45 & 30 & 55 & 15 \\
\hline
\end{tabular}

Table 4 shows a positive dynamics in the formation of this criterion and its indicators.. At the control stage, the number of children with a high level increased, and the number of children with a low level decreased.

The dynamics of dialogical speech development criteria is presented in Table 5

Table 5. The dynamics of dialogical speech development criteria

\begin{tabular}{|c|c|c|c|c|c|c|}
\hline \multirow{3}{*}{$\begin{array}{c}\text { Criteria for } \\
\text { the } \\
\text { development } \\
\text { of dialogical } \\
\text { speech }\end{array}$} & \multicolumn{3}{|c|}{$\begin{array}{c}\text { Ascertaining } \\
\text { experiment }\end{array}$} & \multicolumn{3}{|c|}{$\begin{array}{c}\text { Control } \\
\text { experiment }\end{array}$} \\
\hline & \multicolumn{6}{|c|}{ Level (\%) } \\
\hline & .00 & $\stackrel{\Xi}{\Xi}$ & 3 & .000 & : & 芬 \\
\hline Sociability & 15 & 70 & 15 & 40 & 50 & 10 \\
\hline $\begin{array}{l}\text { Ability to } \\
\text { adequately } \\
\text { respond to any } \\
\text { treatment }\end{array}$ & 15 & 35 & 50 & 40 & 50 & 10 \\
\hline $\begin{array}{l}\text { Ability to } \\
\text { engage in a } \\
\text { dialogue }\end{array}$ & 15 & 40 & 45 & 40 & 50 & 10 \\
\hline $\begin{array}{l}\text { Ability to } \\
\text { observe } \\
\text { dialogue rules }\end{array}$ & 15 & 40 & 45 & 30 & 55 & 15 \\
\hline
\end{tabular}

Table 5 shows a positive dynamics in the formation of this criterion and its indicators. At the ascertaining stage, the medium and low levels of development of dialogical speech predominated. The high level was observed only in $15 \%$. At the control stage, the medium and high levels of development of dialogical speech became predominant. The low level was observed only in $10 \%$.

A comparison of the results of the ascertaining and control stages indicates a positive dynamics of the level of development of dialogical speech in older preschoolers. Generalization of these data, analysis of qualitative and quantitative characteristics allowed us to identify the level of dialogical speech of older preschoolers in general. Figure 1 presents a comparative diagram of the results of the ascertaining and control 
stages of the experiment on the development of dialogical speech in preschool children.

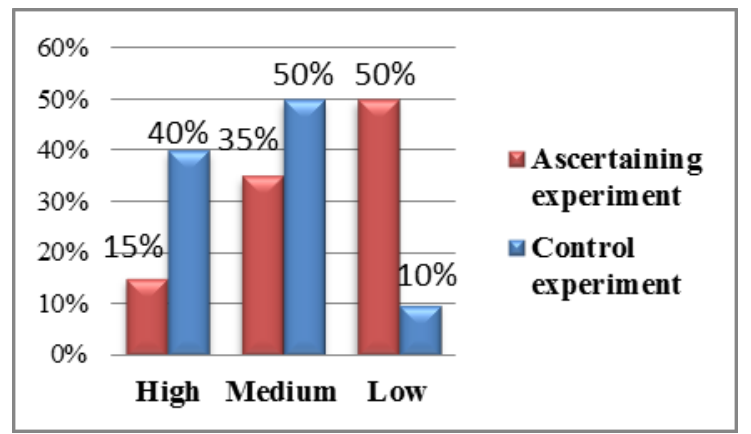

Fig. 1. Comparison of the results of the ascertaining and control stages of the experiment on the development of dialogical speech in senior preschoolers

Figure 1 shows that at the control stage, the number of children with a low level of dialogical speech development significantly decreased from $50 \%$ to $10 \%$. The number of children with a high level increased from $15 \%$ to $40 \%$, and with a medium level - increased from $35 \%$ to $50 \%$. The significance of differences was proved using the t-Student test.

\section{Conclusion}

The study justified the need to use forms of nonsituational-personal communication and performances in developing dialogical speech in preschoolers as a condition for including children in game situations aimed at developing an ability to enter into a dialogue with peers, and observe elementary rules are confirmed dialogue culture.

The theoretical and practical significance includes: the significance of non-situational-personal communication as a psychological mechanism for the development of dialogical speech and dialogical skills in preschool children; establishing determinative relations between the form of non-situational-personal communication and the potential of theatrical games, allowing to form the dialogical speech of senior preschool children in the context of game situations during theatrical activities; these game situations can be applied in theatrical activities. The inclusion of game situations in theatrical activities provides qualitative changes in meaningful characteristics of dialogical speech in senior preschoolers.

\section{References}

1. L.S. Vygotsky, The Game and Its Role in the Psychological Development of the Child Developmental Psychology, 56-79 (St. Petersburg: Peter, 2001)

2. A.A. Leontyev, Psychology of Communication, 3, 365 (Moscow: Smysl, 2000)

3. M.I. Lisina Formation of a child's personality in communication, 320, (St. Petersburg: Peter, 2009)

4. On approval of the federal state educational standard for preschool education: Order of the Ministry of Education and Science of the Russian Federation of October 17 Retrieved from: http://www.consultant.ru/ (2013).

5. On the Concept of the Federal Target Program for the Development of Education for 2016-2020: Order of the Government of the Russian Federation of 29.12 // Retrieved from: http://www.consultant.ru/ (2012).

6. G.G. Tustina, A.O. Stepanenko, Study of the development of dialogical speech in senior preschool age, Science and education, preserving the past, creating the future: Collection of articles of the XIII International Scientific and Practical Conference: in 3 parts 306-312 (2017).

7. J. Piaget Speech and thinking of the child. Genesis of elementary logical structures: Classification and Seriation, 408, (Moscow: EKSMO-Press, 2002).

8. E.O Smirnova., A.N Veraksa., D.A Bukhalenkova., I.A Ryabkova. Relationship between Play Activity and Cognitive Development in Preschool Children. Kul'turno-istoricheskaya psikhologiya CulturalHistorical Psychology, 14, 1, 4-14, (2018) 